\title{
Beliefs and Experiences of Fear of Hypoglycemia and Use of Uncooked Cornstarch before Bedtime in Persons with Type 1-Diabetes
}

\author{
Therese Anderbro1,2, Erik Moberg3, Ulf Adamson², Per-Eric Lins'², Unn-Britt Johansson ${ }^{4,5}$ \\ ${ }^{1}$ Stockholm University, Department of Psychology, Stockholm, Sweden \\ ${ }^{2}$ Karolinska Institutet, Department of Clinical Sciences, Danderyd Hospital, Stockholm, Sweden \\ ${ }^{3}$ Karolinska Institutet, Department of Medicine, Karolinska University Hospital, Huddinge, Stockholm, Sweden \\ ${ }^{4}$ Sophiahemmet University, Stockholm, Sweden \\ ${ }^{5}$ Karolinska Institutet, Department of Clinical Sciences and Education, Södersjukhuset, Stockholm, Sweden \\ Email: therese.anderbro@psychology.su.se
}

How to cite this paper: Anderbro, T., Moberg, E., Adamson, U., Lins, P.-E. and Johansson, U.-B. (2018) Beliefs and Experiences of Fear of Hypoglycemia and Use of Uncooked Cornstarch before Bedtime in Persons with Type 1-Diabetes. Open Journal of Nursing, 8, 795-810.

https://doi.org/10.4236/ojn.2018.811060

Received: October 22, 2018

Accepted: November 18, 2018

Published: November 21, 2018

Copyright $\odot 2018$ by authors and Scientific Research Publishing Inc. This work is licensed under the Creative Commons Attribution International License (CC BY 4.0).

http://creativecommons.org/licenses/by/4.0/

\begin{abstract}
Introduction: Among persons living with type 1-diabetes hypoglycemia and fear of hypoglycemia remain limiting barriers for achieving optimal glucose control and a good quality of life. Fear of hypoglycemia has been found stable over time if not treated. Uncooked cornstarch has been found to reduce the risk of hypoglycemia but has not been studied in relation to fear of hypoglycemia. The aims of this study were to through clinical data, self-reported measures and clinical interviews explore subjects' experience of using uncooked cornstarch before bedtime and their beliefs and experiences of fear of hypoglycemia. Methods: Mixed methods with both quantitative and qualitative data were used. Self-reported measures of hypoglycemia and fear of hypoglycemia were compared to subjects' responses during a clinical interview. The interviews were analyzed with a functional behavior analytical approach. Results: A total of five subjects took part in the study. One subject perceived the uncooked cornstarch helpful in reducing hypoglycemia. Several subjects could recall frightening hypoglycemic episodes triggering their fear. Three out of the five subjects reported avoidance behaviors such as excessive self-monitoring of blood glucose or overeating related to fear of hypoglycemia. Conclusions: The uncooked cornstarch was found appetizing but was not perceived as having an effect on BG or hypoglycemia frequency. The clinical interviews confirmed previous research regarding experience of hypoglycemia and fear of hypoglycemia.
\end{abstract}




\section{Keywords}

Adults, Fear of Hypoglycemia, Experiences, Type 1 Diabetes, Uncooked Cornstarch

\section{Introduction}

Hypoglycemia and fear of hypoglycemia $(\mathrm{FoH})$ remain the greatest limiting factors in achieving glycemic control in type 1 diabetes [1]. The global HAT study found that overall hypoglycemia rates were high and rates of any-, nocturnal $(\mathrm{NH})$ and severe hypoglycemia (SH) were 73.3, 11.3 and 4.9 events/patient-year for persons with type 1 diabetes [2]. Hypoglycemia is the most feared complication of diabetes [3]. A majority of persons with type 1 diabetes report experiencing FoH [4] with fear being more common in those above 50 years of age according to a recent study [5]. Böhme et al. [5] found that nearly $70 \%$ of those older than 50 reported FoH whereas $43.5 \%$ did in the group under the age of 18 . It is noted that women experience higher FoH than men [5] [6] [7]. Hypoglycemia experiences could influence the person's behaviors used in self-management to include more frequent self-monitoring of blood glucose, more contact with health care provider and to reduce attendance in the workplace. In addition, FoH could also lead to dysfunctional self-care behaviors including reduction in or skipping of insulin doses, excess calorie intake and avoidance of physical activity [8].

Furthermore FoH is associated with problems with anxiety and with poorer QoL [5] [7]. Partners also report hypoglycemia fear being a major concern [9]. A recent study found that $\mathrm{FoH}$ was associated with greater glycemic variability and higher caloric intake and less physical activity [10]. Women have reported high levels of external eating styles which mean eating for non-nutritive reasons and this was associated with high level of diabetes distress and could be related to strategies to avoid the threat of hypoglycaemia [11]. FoH seems to be greater at night and could contribute to poor sleep quality [12]. Experience of frequent nocturnal hypoglycemia $(\mathrm{NH})$ or frequent severe hypoglycaemia $(\mathrm{SH})$ is associated with greater $\mathrm{FoH}$ in persons with type 1 diabetes [6] [7]. Continuous glucose monitoring has showed that $52 \%-84 \%$ of persons with type 1 diabetes develop biochemical hypoglycemia during sleep, even if these events are mostly asymptomatic and their severity is difficult to determine [13] [14]. The effects of $\mathrm{NH}$ events continued longer than those of daytime events in individuals with type 1 diabetes 10.6 vs. 4.9 hour [15]. Moreover, $\mathrm{NH}$ events had a greater impact on the individual's well-being and work-time on the following day compared with daytime episode [15] [16].

Despite advances in technology, insulin analogs, and evidence-based diabetes management the problem with hypoglycemia and FoH remains [12]. A recent longitudinal study showed that $\mathrm{FoH}$ is stable over time if untreated [17]. Thus 
there is a great need to develop interventions for FoH. Uncooked cornstarch has been used previously to reduce the risk for $\mathrm{NH}$ in young children and adolescents [18] [19] [20] [21] and adults with type 1 diabetes [22]. Furthermore, it has been used as a strategy to lessen the frequency of $\mathrm{NH}$ in persons with type 2-diabetes [22]. Uncooked cornstarch is described as a complex carbohydrate which is slowly absorbed and therefore provides a supportable source of glucose overnight [24]. It has also been used in glycogen storage disease to prevent $\mathrm{NH}$ [25]. A review article analyzed the current state of knowledge on nutritional strategies to prevent $\mathrm{NH}$ in individuals with type 1 diabetes and found some evidence for that uncooked cornstarch in the bedtime snack composition could be useful for prevention of $\mathrm{NH}$. A review article analyzed the current state of knowledge on nutritional strategies to prevent $\mathrm{NH}$ in individuals with type 1 diabetes and found some evidence for that uncooked cornstarch in the bedtime snack composition could be useful for prevention of NH. However, further research is needed to evaluate these nutritional strategies effect on $\mathrm{NH}$ [21]. To date there are no studies examining what effect the uncooked cornstarch may have on FoH or on patients experience of using uncooked cornstarch.

\section{Aims}

This study aimed through clinical data, self-reported measures and clinical interviews to explore:

- The subjects' experience of using uncooked cornstarch before bedtime;

- The subjects' beliefs of how their FoH developed;

- Possible maintaining factors in FoH in order to in the future develop effective interventions for FoH.

\section{Methods}

The study used both a quantitative and qualitative approach with clinical data and self-reported measures of fear of hypoglycemia and hypoglycemic episodes as well as clinical interviews.

\subsection{Subjects}

Subjects were recruited from a previous longitudinal study on fear of hypoglycemia (FoH) in type 1-diabetes [17]. Subjects who in 2014 had reported a high level of FoH and a high risk of severe hypoglycemia $(n=32)$ were asked to participate. A high level of FoH was defined as scoring $\geq 75$ percentile on the Hypoglycemia Fear Survey (HFS) and a high risk of SH as having reported one or more episodes of $\mathrm{SH}$ in the previous 12 months in the above-mentioned study.

\subsection{Materials and Methods}

The study's primary approach was qualitative with an addition of quantitative measures of daytime and nocturnal episodes of hypoglycemia, $\mathrm{HbAlc}, \mathrm{FoH}$ and weight before (baseline) and after the intervention. 
FoH was measured with the Hypoglycemia Fear Survey (HFS) originally developed by Cox et al. [26]. The questionnaire consists of two subscales containing 23 items rated on a five-point Likert scale, 0 (never) to 4 (always). The total sum score ranges from 0 - 92. A higher score indicates higher FoH. The HFS Worry subscale includes 13 items measuring anxiety-provoking aspects of hypoglycemia; scores range from 0 to 52 and the HFS Behavior sub-scale includes 10 items measuring behavior done in order to avoid hypoglycemia or the consequences of hypoglycemia, score range from 0 to 40 . In this study we used a Swedish translation of the Hypoglycemia Fear Survey (Swe-HFS) [27].

The uncooked cornstarch used in this study was in the form of a snack bar (Extend $\mathrm{Bar}^{\bullet}$ ), which comes in different flavors (chocolate, apple-cinnamon, mixed berries and peanut butter). Each bar weighas 40 grams and contains 5 grams of uncooked cornstarch.

The qualitative clinical interview and following analysis was conducted using a behavior analytic approach. The theoretical foundation of behavior analysis is learning theory, a theory to which Pavlov and Skinner, among many others have contributed with the principals of classical and operant conditioning [28]. Included here is also cognitive aspects developed by Bandura and Beck etc [29]. Behavior analysis as a method has previously been used in research resulting in effective treatment of for instance anxiety, depression and autism [30]. Thus the method is suitable for obtaining a deeper knowledge and understanding of the phenomenon $\mathrm{FoH}$ regarding what different factors may trigger reactions of $\mathrm{FoH}$, how the individual may behave in these situations, how the person handles FoH and what types of consequences occur. The latter would be considered the maintaining factors of $\mathrm{FoH}$. In a behavior analysis present circumstances are analyzed as well as how these circumstances have developed historically.

The interviews in this study thus had a clinical focus on the experience of using uncooked cornstarch and how each subject perceived its effect on BG-levels and $\mathrm{FoH}$ as well as on the subject's previous experience of hypoglycemia and FoH. Questions on experience and handling of hypoglycemia and FoH were asked in order to explore possible triggering and maintaining factors of $\mathrm{FoH}$ in order to do a functional behavior analysis on $\mathrm{FoH}$ for each subject [28]. Each interview was guided by an interview schedule, developed by the first author based on the literature and professional experience. The interviews were transcribed verbatim and each interview was read through several times before identifying text related to each theme. In the analysis the subjects' answers were related to quantitative results from scores on HFS, self-reported frequencies of hypoglycemia and HbAlc.

\subsection{Procedure}

Subjects were instructed to self-register daytime and nocturnal episodes of hypoglycemia during one month before starting the intervention with the uncooked cornstarch using a diary sent to them by mail. A research nurse took baseline measures of $\mathrm{HbAlc}$ and weight during a visit to the medical clinic one 
month later. Duration of diabetes was collected from medical records. During the visit, the subjects also filled out baseline HFS and were informed about when to eat the uncooked cornstarch during the study, i.e. to eat one to two snack bars before going to bed at night. Subjects were instructed to continue to self-register daytime and nocturnal episodes of hypoglycemia during the two-month intervention and to proceed with the remaining self-care as usual. After the two-month intervention period measures were again taken using the same procedure as at baseline.

Within a month after the intervention period, a diabetes-educated psychologist conducted a semi-structured audiotaped interview, which lasted 60 minutes with each subject.

\subsection{Statistical Analysis}

Statistical analysis was conducted using SPSS 22.0 (SPSS Inc., Chicago, IL, USA). Descriptive statistics were used for demographic and clinical data. Changes in FoH was also evaluated using the criterion for Minimum Clinically Important Difference (MID) as identified by Stargardt et al. [31] where the mean difference in HFS-Worry score between those experiencing a severe event of hypoglycemia and those without $\mathrm{SH}$ is considered MID which here is a difference of 5.5 points on HFS Worry.

\subsection{Ethical Consideration}

The study was approved by the regional ethical review board, DNR 20151550-31-4.

\section{Results}

A total of five persons (three women and two men) out of the 32 eligible participated in the clinical interviews. The mean age was $62 \pm 12$ years, mean duration 46.6 years \pm 12.8 and mean $\mathrm{HbA1c} 63 \mathrm{mmol} / \mathrm{mol} \pm 9.8$. Demographic, clinical and self-reported data on fear of hypoglycemia is presented in Table 1.

\subsection{The Subjects' Experience of Using Uncooked Cornstarch before Bedtime}

Themes that were explored were the subjects' experience of the edibility of the

Table 1. Demographic, clinical and self-reported data for the five subjects.

\begin{tabular}{ccccccccccc}
\hline Subject & Gender & Age & $\begin{array}{c}\text { Diabetes } \\
\text { duration }\end{array}$ & $\begin{array}{c}\text { Marital } \\
\text { status }\end{array}$ & $\begin{array}{c}\text { HbA1c } \\
2016 \\
\text { pre }\end{array}$ & $\begin{array}{c}\text { HbAlc } \\
2016 \\
\text { post }\end{array}$ & $\begin{array}{c}\text { HFS- } \\
\text { score } \\
2010\end{array}$ & $\begin{array}{c}\text { HFS- } \\
\text { score } \\
2014\end{array}$ & $\begin{array}{c}\text { HFS- } \\
\text { score }\end{array}$ & $\begin{array}{c}\text { HFS- } \\
\text { 2016 pre }\end{array}$ \\
\hline 1 & Male & 80 & 50 & Married & 51 & 48 & 48 & 48 & 38 & 37 \\
2 & Female & 60 & 47 & Married & 61 & 61 & 61 & 78 & 73 & 73 \\
3 & Female & 47 & 30 & Divorced & 79 & 79 & 22 & 44 & 39 & 33 \\
4 & Male & 70 & 60 & Married & 53 & 48 & 49 & 42 & 53 & 54 \\
5 & Female & 50 & 46 & Married & 66 & 63 & 28 & 40 & 30 & 44 \\
\hline
\end{tabular}


cornstarch bar, the influence on glucose levels and the influence on hypoglycemia frequency.

Edibility

Four out of the five subjects found the cornstarch bars in good taste. One person said:

"If I felt like mm, it would be nice to have some chocolate, (that usually indicates my sugar is getting low) then $P d$ eat an Extend bar, and it was just like ... my sweet tooth disappeared, but the blood sugar still kept falling."

This person also experienced a weight gain of $1.5 \mathrm{~kg}$ during the intervention period and expressed concern about this.

Another person, who experienced problems with jaw and teeth found the bar to be somewhat hard to chew and therefore dissolved the bars in milk.

Influence on glucose levels

The subjects expressed mixed experiences of how the cornstarch affected glucose levels. One person experienced higher glucose levels in the mornings. Yet another was very positive.

"Well, it was actually a good thing, because in these two months (pauses) my blood sugars were in balance actually, both during the night and in the following day, because they (cornstarch bars, authors remark) had a long lasting effect".

The remaining three interviewed subjects did however not experience an effect on glucose levels.

Influence on hypoglycemia frequency

Using cornstarch before bedtime was experienced as helpful in eliminating nocturnal hypoglycemia in one subject whereas three subjects expressed that the cornstarch had no effect on hypoglycemia frequency. The fifth subject had expected a positive effect that did not occur when BG was checked. Furthermore, the same subject reported more hypoglycemic episodes during the intervention but referred them to a change in other living habits during the intervention period. Individual scores on HFS worry, HFS Behavior, frequency of nocturnal and daytime hypoglycemia pre and post intervention is found in Figures 1-4.

\subsection{The Subjects' Beliefs of the Origin of FoH and Possible Maintaining Factors}

Frequency of nocturnal and daytime hypoglycemia, experience of severe hypoglycemia, hypoglycemia symptoms, strategies preventing and treating hypoglycemia and the role of kindred were explored as well as possible triggering and maintaining factors of fear of hypoglycemia. Results are presented for each subject.

\section{Subject 1}

Hypoglycemia history and symptoms

This person experienced hypoglycaemia when being physically active during walks, playing golf but he could not estimate how often. He reported that a nocturnal hypoglycemia occurred about once a month. He had experienced many 


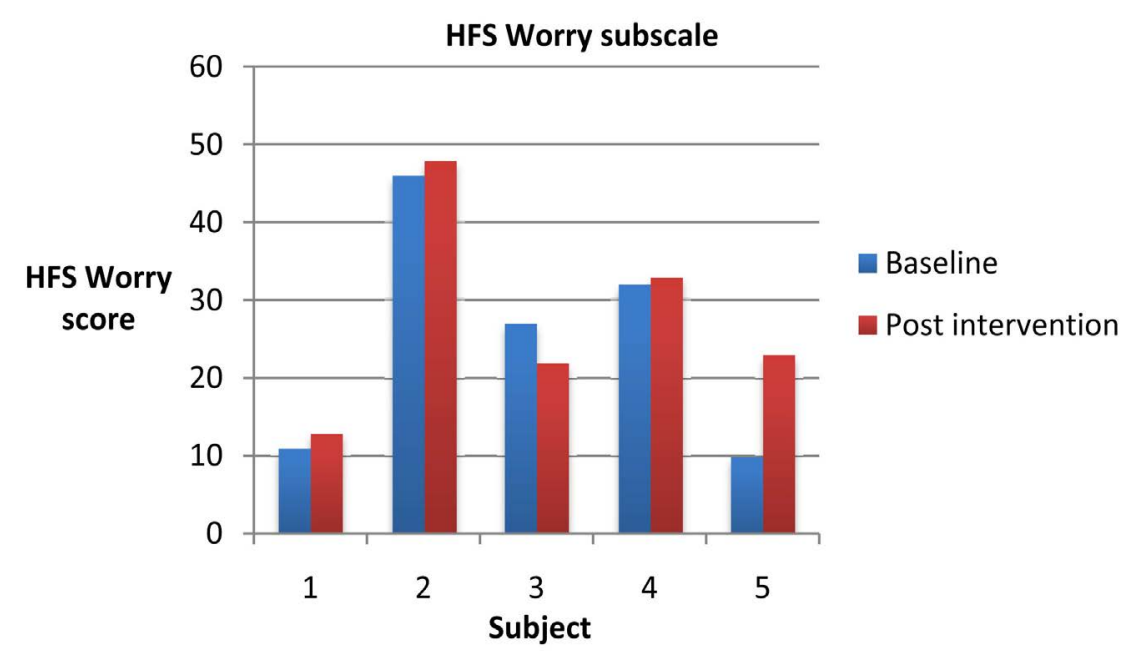

Figure 1. HFS-Worry sub-scale score for each subject at baseline and post intervention.

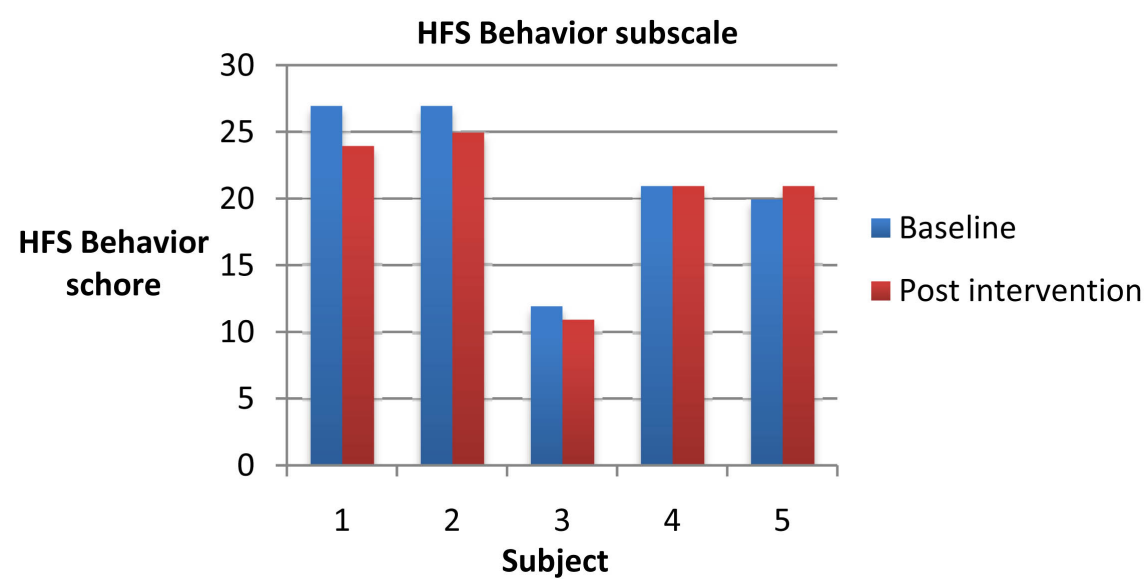

Figure 2. HFS-Behavior sub-scale score for each subject at baseline and post intervention.

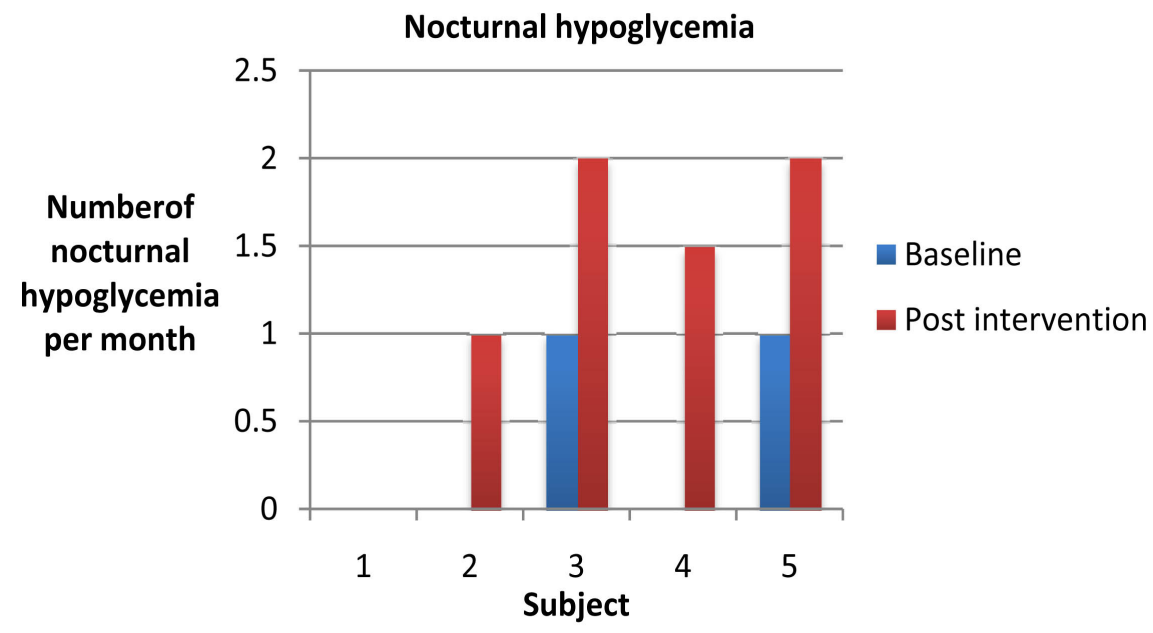

Figure 3. Number of nocturnal hypoglycemia per month for each subject at baseline and post intervention. 


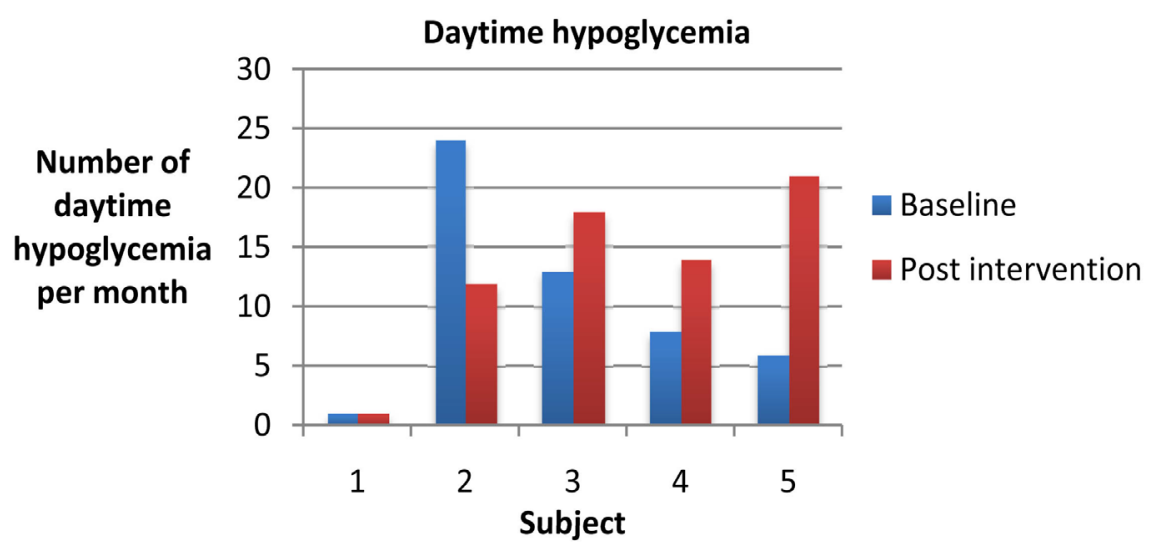

Figure 4. Number of daytime hypoglycemia per month for each subject at baseline and post intervention.

severe episodes of hypoglycemia and had several times had to go by ambulance to the hospital.

\section{Preventing and treating hypoglycemia}

In the case of nocturnal hypoglycemia he described usually waking up feeling low and then drinking milk or eating something sweet. To prevent daytime hypoglycemia he avoided going for walks before he has his mid-morning coffee with a sandwich or cake. He reported always bringing a banana or some chocolate when being physically active but emphasized that he did not allow diabetes to prevent him from doing anything.

\section{The role of kindred}

The subject described his wife as being very important in his diabetes care and especially concerning hypoglycemia.

"We are a good team".

His wife was good at detecting low glucose in the patient and woke him or made sure he ate something.

\section{Fear of hypoglycaemia}

During the interview the subject expressed a low degree of fear of hypoglycemia (from 0 to 5 on a scale from 0 to 10 ).

"P m extremely rarely worried".

On HFS-Worry subscale he had a low score (Figure 1). His wife said he was more worried about high glucose values. She on the other hand was worried about him having hypoglycaemia. The subject described appropriate strategies preventing and treating hypoglycemia such as checking glucose and eating when low. Hedid not describe any avoidance behavior related to hypoglycemia. Histotal scores on the HFS were fairly stable since 2010 (Table 1) with no MID in HFS Worry during the intervention (Figure 1). There was also no difference in the subjects self monitored frequency of hypoglycemia (Figure 3 and Figure 4).

\section{Subject 2}

\section{Hypoglycemia history and symptoms}

The subject estimated that she has a hypoglycemic episode on average every 
$4^{\text {th }}$ day and believed it was linked to her stress level. Sometimes they occurred on a daily bases. Nocturnal hypoglycemia occurred once every other month and she usually woke up when this happened. She experienced approximately five severe hypoglycemic episodes of which three had led her to be hospitalized. Since her first pregnancy she suffered from impaired awareness and could no longer detect symptoms. Earlier she could notice cognitive symptoms as well as a change in mood;

"I became kind, dumb and slow".

Preventing and treating hypoglycemia

Frequently measuring BG (8 times/day) was her primary strategy to prevent hypoglycemia. She also made sure not to go to bed if BG was below 6 . Because of impaired awareness she applied external signals to detect hypoglycemia such as time since meal in addition to stress level:

"Let's see, it's been three hours since I ate and my BG was only six this morning. Then it may be low, and I have had a quiet morning without stress which usually makes BG drop faster. Pve learned to put together all the factors, I think."

The role of kindred

People around her noticed her being hypoglycemic before she did, especially her adult children who also would tell her to eat something in a way that did not make her upset. Her husband however, did not notice as often and there was often a conflict if he said anything. She described being angry with him for not showing enough interest in her diabetes. For instance, not participating in diabetes education or doctors visits.

Fear of hypoglycaemia

She expressed fear of hypoglycemia but said that fear of hyperglycemia and long-term complications such as going blind or having to amputate a leg were even greater. Worrying about hypoglycemia occurred when she did physical exercise or was at an event. Her main fear was that no one would find her when she was unconscious and that she therefore would die from the episode. The subject could recall several frightening hypoglycemic episodes, the first one being her very first severe hypoglycemia. She was in her late teens, riding her bike with some older friends when she became unconscious. The starting point of her fear of hypoglycemia she believed was in the hospital when she was diagnosed with type 1diabetes:

"No, I do remember the very first time I had a hypo and it was a provoked hypo at night at this children's hospital. ... and then... I actually think someone woke me up who patted me and said' (subject's name), you need to remember how you feel now, because this is low blood sugar"

The subject described that she earlier in life checked her BG compulsively as a strategy to avoid both hypo- and hyperglycemia. She used to try to correct BG if it was too high or low leading to an oscillating BG. Furthermore, before physical exercise or an event she made sure her BG was high in order to avoid becoming hypoglycemic. Her HFS-scores had been high since 2010 and increased further 
in 2014 (Table 1). However, there was no MID in HFS Worry during the intervention (Figure 1). Her self-monitored frequency of daytime hypoglycemia indicated fewer episodes during the intervention with uncooked cornstarch than pre-measures (Figure 4). As far as nocturnal episodes she reported none pre-intervention and one during the intervention (Figure 3 ).

\section{Subject 3}

Hypoglycemia history and symptoms

This person had irregular and unpredictable hypoglycemic episodes possibly due to her diabetes being secondary to a pancreatitis. For several weeks she would have no hypoglycemic episodes whereas other weeks were described as "a roller coaster ride" with many episodes. She had impaired awareness with no clear symptoms of hypoglycemia.

Preventing and treating hypoglycemia

Because of the impaired awareness she relied on the alarm on her Dexcom to warn her. She brought dextrose with her and at home she used honey to treat a hypoglycemia.

"So I just take a spoon of honey and place it inside my cheek. There are so many blood vessels there so just ... slurp! Much faster acting than otherwise"

The role of kindred

Her mother and children noticed when her BG was low, as well as her cat who then bite her. All of them were, according to her, helpful and supportive. However, she also described that her ex-husband was not supportive while they were married.

Fear of hypoglycaemia

This subject did not describe any fear of hypoglycemia currently as well as historically.

"It happens - and so what? I can't control it. Should I be scared of something I can't control? No?'

Interestingly though her HFS-score had doubled between 2010 and 2014 from 22 to 44 and in 2016 remained higher in 2016 (Table 1). There was no MID in HFS Worry during the intervention (Figure 1). Her self-monitored frequency of daytime hypoglycemia indicated the same level of episodes during the intervention with uncooked cornstarch than pre-measures (Figure 4). As far as nocturnal episodes she reported one pre-intervention and two during the intervention (Figure 3).

\section{Subject 4}

\section{Hypoglycemia history \& symptoms}

He rarely had hypoglycemic episodes unless he changed insulin regimen. On a few occasions he had become unconscious due to hypoglycemia. This had happened in social situations. The clearest hypoglycemia symptoms for him were sweating and a change in his sense of humor as he become ironic in his joking when low.

Preventing and treating hypoglycemia

When he was low he drank fruit juice. To prevent hypoglycemia he brought 
sweets with him.

\section{The role of kindred}

While they were married his ex-wife used to notice when he had a hypoglycemic episode.

Fear of hypoglycaemia

The subject described that he had always been more afraid of hypoglycemia than hyperglycemia. According to him he was at his best when his BG was a little higher than optimal. His fear of hypoglycemia was about loosing control or performing badly at work. The subject experienced a severe hypoglycemia while at work abroad in the beginning of his career and was admitted to hospital. That experience was according to him, what triggered his fear. He coped with his fear by eating and did not abstain from any activities because of his fear. His scores on the HFS were fairly stable since 2010 (Table 1) with no MID in HFS Worry during the intervention (Figure 1). There was however an increase in the subjects self monitored frequency of hypoglycemia during the intervention (Figure 3 and Figure 4).

\section{Subject 5}

Hypoglycemia history and symptoms

Hypoglycemia frequency varied greatly for this subject. During the study period she experienced approximately three to four episodes a week. She had had several severe episodes, all of which had occurred during night time while asleep. One episode, according to her, was so severe that she nearly died from it. The main symptoms were related to mood as she became aggressive and shouted, but she had also had seizures. Daytime symptoms were tiredness, stiffness, a cold sweat and shakiness. She had during a few time periods experienced impaired awareness related to trying to keep her BG low.

Preventing and treating hypoglycemia

To prevent hypoglycemia she frequently checked her BG. If low she ate whatever was at hand.

\section{The role of kindred}

This person described that hypoglycemia had affected her family, both her husband and her child in a negative way. Her husband did not understand that she could not control her behavior when hypoglycemic and therefore often become accusatory towards her. Her child had seen her having a severe hypoglycemia and was terrified by the experience.

\section{Fear of hypoglycaemia}

The subjects fear was primarily that a nocturnal hypoglycemic episode where she became aggressive or had a seizure could traumatize her child. This fear had increased lately due to the recent severe episodes her child had witnessed. She reported experiencing shame related to her behavior during nocturnal hypoglycemia but not related to daytime episodes. She coped with her fear by frequent BG-testing and by keeping her BG high to be on the safe side especially at night. She did not go to bed until her BG was above 10. Her increased scores on HFS from 2010 to 2014 corroborated the increased $\mathrm{FoH}$ she reported on during the 
interview (Table 1). There was an MID in HFS Worry during the intervention (Figure 1) as well as an increase in hypoglycemia frequency (Figure 3 and Figure 4).

\section{Discussion}

In this study we have through clinical data, self-report measures and semi-structured clinical interviews explored beliefs and experiences of fear of hypoglycemia and use of uncooked cornstarch before bedtime in five persons with type 1-diabetes.

\section{The subjects' experience of using uncooked cornstarch before bedtime}

In the interviews subjects reported that the uncooked cornstarch given to them as a snack-bar was found appetizing for most of them which is a basic condition for this being a possible intervention. There was however a low perception of the cornstarch affecting BG in general and hypoglycemia in specific. Perhaps the dosage of uncooked cornstarch was too low for an effect as the subject ate one bar containing 2 - 4 grams and studies reporting an effect on nocturnal hypoglycemia used a bar containing 5 grams [23].

\section{The subjects' beliefs of the origin of FoH and possible maintaining factors}

Several subjects could recall frightening hypoglycemic episodes and believed these to be what historically triggered their FoH, something that earlier research supports [6]. The interviews revealed that four out of the five subjects during some time period had experienced impaired hypoglycemic awareness and all of them had experienced several episodes of severe hypoglycemia. Both of these factors are associated with FoH [6]. Several of the subjects described losing control of their behavior as their main fear but also fear of not waking up or even dying from the hypoglycemia emerged.

Regarding maintaining factors subjects two, four and five all reported using avoidance behaviors such as excessive BG-testing, overeating and limiting activities to avoid or reduce FoH. All of these behaviors are previously known to be common strategies to reduce FoH [32]. The problem with these avoidance behaviors is that the fear reduction is short-term and in fact maintains the person's fear, can lead to an increased risk of long-term complications and reduces QoL [33]. The remaining two subjects (one and three) did not express FoH during the interviews while their HFS-scores were comparable to the other three subjects. The discrepancy between HFS-score and interviews is somewhat puzzling. One plausible explanation may be that these subjects found it easier to report FoH through the more anonymous HFS than during an interview with a psychologist.

All of the subjects described that kindred were helpful in detecting and in some instances, treating hypoglycemia. Some reported their partner as supportive whereas others received more support from children or parents. The latter subjects instead experienced their partner as non-supportive and even accusatory when they were hypoglycemic. It is well known that experience of severe 
hypoglycemia is associated with conflicts about diabetes management in close relationships [34].

An interesting find is that several of the subjects described also having fear of hyperglycemia. This may lead to a constant balancing act where the threat of either being too high or too low is ever present and may lead to a feeling of being trapped or a feeling of helplessness such as reported by Shiu (2002) [35].

\section{Strengths and limitations}

The foremost strength of this study is the combination of quantitative and qualitative methods. Furthermore longitudinal data enables us to compare FoH over time and relate this to the interviews. A limitation is that only 5 out of 32 eligible subjects agreed to be included in the study. This together with the facts that the subjects were all relatively old, had long diabetes durations limits the generalizability of the results. One possible explanation of the low participation rate may be that hypoglycemia and fear is something they are reluctant to share with others. Another explanation may be that they are not comfortable speaking to a psychologist. Another explanation was that the study was too time consuming.

\section{Conclusion}

In conclusion, the uncooked cornstarch in the form of a snack-bar was found appetizing but was not perceived as having an effect on BG or hypoglycemia frequency. Furthermore the clinical interviews confirmed previous research regarding experience of severe hypoglycemia being a common trigger of $\mathrm{FoH}$ as well as using excessive BG-testing, overeating and limiting activities as avoidance behaviors maintaining FoH.

\section{Acknowledgements}

We wish to thank Lena Gabrielsson for assistance.

\section{Funding}

This study was funded by Sophiahemmet University, the Foundation for Medical Research at Sophiahemmet. Furthermore, Consumer Health supported the study.

\section{Conflicts of Interest}

The authors declared no conflicts of interest.

\section{References}

[1] Cryer, P.E. (2008) The Barrier of Hypoglycemia in Diabetes. Diabetes, 57, 3169-3176. https://doi.org/10.2337/db08-1084

[2] Khunti, K., Alsifri, S., Aronson, R., Cigrovski Berković, M., Enters-Weijnen, C., Forsén, T., Galstyan, G., Geelhoed-Duijvestijn, P., Goldfracht, M., Gydesen, H., Kapur, R., Lalic, N., Ludvik, B., Moberg, E., Pedersen-Bjergaard, U. and Ramachandran, A., HAT Investigator Group (2016) Rates and Predictors of Hypoglycaemia in 27585 People from 24 Countries with Insulin-Treated Type 1 and 
Type 2 Diabetes: The Global HAT Study. Diabetes, Obesity Metabolism, 18, 907-915. https://doi.org/10.1111/dom.12689

[3] Pramming, S., Thorsteinsson, B., Bendtson, I. and Binder, C. (1991) Symptomatic Hypoglycaemia in 411 Type 1 Diabetic Patients. Diabet Medicine, 8, 217-222. https://doi.org/10.1111/j.1464-5491.1991.tb01575.x

[4] Anarte Ortiz, M.T., Caballero, F.F., Ruiz de Adana, M.S., Rondán, R.M., Carreira, M., Domínguez-López, M., Machado, A., Gonzalo-Marín, M., Tapia, M.J., Valdés, S., González-Romero, S. and Soriguer, F.C. (2011) Development of a New Fear of Hypoglycemia Scale: FH-15. Psychological Assessment, 23, 398-405. https://doi.org/10.1037/a0021927

[5] Bohme, P., Bertin, E., Cosson, E. and Chevalier, N., GEODE Group (2013) Fear of Hypoglycaemia in Patients with Type 1 Diabetes: Do Patients and Diabetologists Feel the Same Way? Diabetes Metabolism, 39, 63-70.

https://doi.org/10.1016/j.diabet.2012.10.006

[6] Anderbro, T., Amsberg, S., Adamson, U., Bolinder, J., Lins, P.-E., Wredling, R., Moberg, E., Lisspers, J. and Johansson, U.-B. (2010) Fear of Hypoglycaemia in Adults with Type 1 Diabetes. Diabetic Medicine, 27, 1151-1158.

https://doi.org/10.1111/j.1464-5491.2010.03078.x

[7] Anderbro, T., Gonder-Frederick, L., Bolinder, J., Lins, P.-E., Wredling, R., Moberg, E., Lisspers, J. and Johansson, U.-B. (2015) Fear of Hypoglycemia: Relationship to Hypoglycemic Risk and Psychological Factors. Acta Diabetologica, 52, 581-589. https://doi.org/10.1007/s00592-014-0694-8

[8] Aronson, R., Goldenberg, R., Boras, D., Skovgaard, R. and Bajaj, H. (2018) The Canadian Hypoglycemia Assessment Tool Program: Insights Into Rates and Implications of Hypoglycemia From an Observational Study. Canadian Journal of Diabetes, 42, 11-17. https://doi.org/10.1016/j.jcjd.2017.01.007

[9] Polonsky, W.H., Fisher, L., Hessler, D. and Johnson, N. (2016) Emotional Distress in the Partners of Type 1 Diabetes Adults: Worries about Hypoglycemia and Other Key Concerns. Diabetes Technology Therapeutics, 18, 292-297. https://doi.org/10.1089/dia.2015.0451

[10] Martyn-Nemeth, P., Quinn, L., Penckofer, S., Park, C., Hofer, V. and Burke, L. (2017) Fear of Hypoglycemia: Influence on Glycemic Variability and Self-Management Behavior in Young Adults with Type 1 Diabetes. Journal of Diabetes and its Complications, 31, 735-741. https://doi.org/10.1016/j.jdiacomp.2016.12.015

[11] Martyn-Nemeth, P., Quinn, L., Hacker, E., Park, H. and Kujath, A.S. (2014) Diabetes Distress May Adversely Affect the Eating Styles of Women with Type 1 Diabetes. Acta Diabetologica, 51, 683-686. https://doi.org/10.1007/s00592-014-0575-1

[12] Martyn-Nemeth, P., Schwarz Farabi, S., Mihailescu, D., Nemeth, J. and Quinn, L. (2016) Fear of Hypoglycemia in Adults with Type 1 Diabetes: Impact of Therapeutic Advances and Strategies for Prevention-A Review. Journal of Diabetes and its Complications, 30, 167-177. https://doi.org/10.1016/j.jdiacomp.2015.09.003

[13] Chico, A., Vidal-Rios, P., Subira, M. and Novials, A. (2003) The Continuous Glucose Monitoring System Is Useful for Detecting Unrecognized Hypoglycemias in Patients with Type 1 and Type 2 Diabetes but Is Not Better than Frequent Capillary Glucose Measurements for Improving Metabolic Control. Diabetes Care, 26, 1153-1157. https://doi.org/10.2337/diacare.26.4.1153

[14] Choudhary, P., Geddes, J., Freeman, J.V., Emery, J., Heller, R. and Frier, B.M. (2010) Frequency of Biochemical Hypoglycaemia in Adults with Type 1 Diabetes with and without Impaired Awareness of Hypoglycaemia: No Identifiable Differ- 
ences Using Continuous Glucose Monitoring. Diabetic Medicine, 27, 666-672. https://doi.org/10.1111/j.1464-5491.2010.03006.x

[15] Frier, B.M., Jensen, M.M. and Chubb, B.D. (2016) Hypoglycaemia in Adults with Insulin-Treated Diabetes in the UK: Self-Reported Frequency and Effects. Diabetic Medicine, 33, 1125-1132. https://doi.org/10.1111/dme.12878

[16] Geelhoed-Duijvestijn, P.H., Pedersen-Bjergaard, U., Weitgasser, R., Lahtela. J., Jensen, M.M. and Östenson, C.G. (2013) Effects of Patient-Reported Non-Severe Hypoglycemia on Healthcare Resource Use, Work-Time Loss, and Wellbeing in Insulin-Treated Patients with Diabetes in Seven European Countries. Journal of Medical Economics, 16, 1453-1461. https://doi.org/10.3111/13696998.2013.852098

[17] Anderbro, T.S., Amsberg, S., Gonder-Frederick, L., Moberg, E., Adamson, U., Lins, P.-E. and Johansson, U.-B. (2018) A Longitudinal Study of Fear of Hypoglycaemia in Adults with Type 1 Diabetes. Endocrinology, Diabetes and Metabolism, 1, e00013. https://doi.org/10.1002/edm2.13

[18] Detlofson, I., Kroon, M. and Åman, J. (1999) Oral Bedtime Cornstarch Supplementation Reduces the Risk for Nocturnal Hypoglycaemia in Young Children with Type 1 Diabetes. Acta Paediatrica, 88, 595-597. https://doi.org/10.1111/j.1651-2227.1999.tb00005.x

[19] Kaufman, F.R. and Devgan, S. (1996) Use of Uncooked Cornstarch to Avert Nocturnal Hypoglycemia in Children and Adolescents with Type I Diabetes. Journal of Diabetes and its Complications, 10, 84-87. https://doi.org/10.1016/1056-8727(94)00079-4

[20] Kaufman, F.R., Halvorson, M. and Kaufman, N.D. (1995) A Randomized, Blinded trial of Uncooked Cornstarch to Diminish Nocturnal Hypoglycemia at Diabetes Camp. Diabetes Research and Clinical Practice, 30, 205-209. https://doi.org/10.1016/0168-8227(95)01192-7

[21] Kaufman, F.R., Halvorson, M. and Kaufman, N.D. (1997) Evaluation of a Snack Bar Containing Uncooked Cornstarch in Subjects with Diabetes. Diabetes Research and Clinical Practice, 35, 27-33. https://doi.org/10.1016/S0168-8227(96)01360-5

[22] Axelsen, M., Wesslau, C., Lönnroth, P., Arvidsson Lenner, R. and Smith, U. (1999) Bedtime Uncooked Cornstarch Supplement Prevents Nocturnal Hypoglycaemia in Intensively Treated Type 1 Diabetes Subjects. Journal of Internal Medicine, 245, 229-236. https://doi.org/10.1046/j.1365-2796.1999.00432.x

[23] Dyer-Parziale M. (2001) The Effect of Extend Bar Containing Uncooked Cornstarch on Night-Time Glycemic Excursion in Subjects with Type 2 Diabetes. Diabetes Research and Clinical Practice, 53, 137-139. https://doi.org/10.1016/S0168-8227(00)00208-4

[24] Chen, Y.T., Cornblath, M. and Sidbury, J.B. (1984) Cornstarch Therapy in Type I Glycogen-Storage Disease. The New England Journal of Medicine, 310, 171-175. https://doi.org/10.1056/NEJM198401193100306

[25] Shah, K.K. and O’Dell, S.D. (2013) Effect of Dietary Interventions in the Maintenance of Normoglycaemia in Glycogen Storage Disease Type 1a: A Systematic Review and Meta-Analysis. Journal of Human Nutrition and Dietetics, 26, 329-339. https://doi.org/10.1111/jhn.12030

[26] Cox, D.J., Irvine, A., Gonder-Frederick, L., Nowacek, G. and Butterfield, J. (1987) Fear of Hypoglycemia: Quantification, Validation, and Utilization. Diabetes Care, 10, 617-621. https://doi.org/10.2337/diacare.10.5.617

[27] Anderbro, T., Amsberg, S., Wredling, R., Lins, P.-E., Adamson, U., Lisspers, J. and Johansson, U.-B. (2008) Psychometric Evaluation of the Swedish Version of the 
Hypoglycaemia Fear Survey. Patient Education and Counselling, 73, 127-131. https://doi.org/10.1016/j.pec.2008.03.022

[28] Bouton, M.E. (2016) Learning and Behavior. A Contemporary Synthesis. 2nd Edition, Sinauer Associates Inc, Sunderland, USA.

[29] Sundel, M. and Sundel, S. (2004) Behavior Change in the Human Services. Behavioral and Cognitive Principles and Applications. 5th Edition, SAGE Publications Inc, USA.

[30] Eikeseth, S. and Svartdal, F. (2007) Tillämpad beteendeanalys: Studentlitteratur AB, Lund, Sweden. (Swedish)

[31] Stargardt, T., Gonder-Frederick, L., Krobot, K.J. and Alexander, C.M. (2009) Fear of Hypoglycaemia: Defining a Minimum Clinically Important Difference in Patients with Type 2 Diabetes. Health and Quality of Life Outcomes, 7, 91. https://doi.org/10.1186/1477-7525-7-91

[32] Wild, D., von Maltzahn, R., Brohan, E., Christensen, T., Clauson, P. and Gonder Frederic, L. (2007) A Critical Review of the Literature on Fear of Hypoglycemia in Diabetes: Implications for Diabetes Management and Patient Education. Patient Education and Counseling, 68, 10-15. https://doi.org/10.1016/j.pec.2007.05.003

[33] Strandberg, R.B., Graue, M., Wentzel-Larsen, T., Peyrot, M., Wahl, A.K. and Rokne, B. (2017) The Relationships among Fear of Hypoglycaemia, Diabetes-Related Quality of Life and Psychological Well-Being in Norwegian Adults with Type 1 Diabetes. Diabetes Research and Clinical Practice, 124, 11-19. https://doi.org/10.1016/j.diabres.2016.12.018

[34] Gonder-Frederick, L., Cox, D., Kovatchev, B., Julian, D. and Clarke, W. (1997) The Psychosocial Impact of Severe Hypoglycemic Episodes on Spouses of Patients with IDDM. Diabetes Care, 20, 1543-1546. https://doi.org/10.2337/diacare.20.10.1543

[35] Shiu, A.T. and Wong, R.Y. (2002) Fears and Worries Associated with Hypoglycaemia and Diabetes Complications: Perceptions and Experience of Hong Kong Chinese Clients. Journal of Advanced Nursing, 39, 155-163.

https://doi.org/10.1046/j.1365-2648.2002.02255.x 